\title{
Normativity, system-integration, natural detachment and the hybrid hominin
}

\section{Lenny Moss ${ }^{1}$}

Published online: 19 June 2020

(C) The Author(s) 2020

\begin{abstract}
From a subjective point of view, we take the existence of integrated entities, i.e., ourselves as the most unproblematic given, and blithely project such integrity onto untold many "entities" far and wide. However, from a naturalistic perspective, accounting for anything more integral than the attachments and attractions that are explicable in terms of the four fundamental forces of physics has been anything but straightforward. If we take it that the universe begins as an integral unity (the singularity referred to as "the cosmic egg") and explodes into progressive stages of internal detachment, then we can also fathom the idea that eddies of relative detachment becoming increasingly integral. Helmuth Plessner made a powerful case for the onset of "positionality" constituting one of the major transitions in nature. Surely, the emergence of "entities" (i.e., life-forms) that position themselves in relation to their surround marks a decisive transition in relative levels of detachment and some would say "autonomy." It would follow, with no less force, that where and when entities can be seen to be normatively integrated, and indeed to be the agents of their own normativity, that another threshold of detachment has been crossed. The paper introduces and explores the idea that normativity, embedded in a wide-ranging theory of natural detachment, can be considered an emergent force of nature that is requisite to accounting for levels of integration beyond that which is explicable in terms of the four fundamental forces of physics. Following this line of enquiry, we argue that the first expression of a fully, normatively-integrated life-form is neither a spoken language user nor for that matter an individual but rather the neoteny-based, Homo erectus Group. In so doing we claim to have made an inroad into embedding the force of normativity into a wide-ranging naturalist framework, to have provided philosophical anthropology with a new (post-individualist) point of departure, and at least playfully, to have given some naturalistic grist to Hegel's proclamation that spirit (Geist) is the truth of nature.
\end{abstract}

Keywords Normativity · Detachment $\cdot$ Hybrid hominin $\cdot$ System integration $\cdot$ Homo erectus $\cdot$ Plural-self awareness $\cdot$ Cerebral asymmetry $\cdot$ Mimesis

Lenny Moss

dcimorse@icloud.com

1 Department of Sociology, Philosophy and Anthropology, University of Exeter, Exeter EX44RJ, UK 


\section{Natural integration and natural normativity}

The problem of natural integration, or perhaps unification - the constitution of a unity is a truly hard problem that has seldom if ever been addressed as such. Indeed, it is perhaps the hard problem of the philosophy of life and mind. Granted, how a natural entity can have interiority, i.e., subjectivity, is a hard problem, but if the question of integration and unification is not identical to the "Hard Problem of Consciousness" (Chalmers 1995) it is also inseparable from it and surely a presupposition of the very possibility of interiority. Nor would even an understanding of how subjectivity could be resident to a single cell tell us how consciousness could become an integrated unity across many cells. If we assume consciousness is a physically based phenomenon, and that it draws upon the activity of various parts of the brain, let alone constituent cells, then we must face our deficits in understanding how the experience of a unified consciousness is realized at the level of an integration of some cells but not others albeit in the absence of evident, non-arbitrary, physical boundaries.

Both more fundamental than the Hard Problem of Consciousness, and more expansive in scope, the problem of integration/unification is also central to the problem of the origin(s) of life. If merely conventionally mechanistic associations of parts outside of parts (partes extra partes) ${ }^{1}$ were sufficient for creating a living unit, it would have been achieved long since. The fact that a natural bacterial chromosome could be successfully replaced by an artifactual chromosome only further testifies to the irreducible importance of a naturally integrated unit, the bacterial cell, as the prior condition of possibility for any molecular configuration, natural or artificial, to be a chromosome. ${ }^{2}$ Perennial claims by biologists to have solved the problem of the origins of life have either been projections based upon the largely uncritical metaphysics of informational idealism (masquerading as consensual science), or based on the largesse of liberal promissory notes fueled by commercial marketing interests.

Lest there be any doubt, I do not aspire to overcome the problem of integration tout court in this paper. Beyond thematizing it as a problem (a worthy endeavor in itself, I claim) I will want to explore the role of "normativity" in hominin/human integration and toy with the idea of normativity being a force of nature. Clearly doing so, if feasible at all, would require a radical expansion, along with a capacity for scaling, of our current concept of normativity. I hope to at least provide some adumbration of what that might look like.

For Leibniz, Kant and Hegel (among others) normativity plays a central role in the understanding of life and mind, albeit in different ways. Hegel, for our present naturalistically oriented purposes, is of most interest because he comes the closest to offering an account of the transition between a pre (or perhaps proto?) normative

\footnotetext{
${ }^{1}$ I first heard the wonderfully mellifluous phrase "partes extra partes" when uttered by Charles Taylor in lectures, possibly his lectures on Hegel at Berkeley in 1981. Taylor himself took the phrase from MerleauPonty.

${ }^{2}$ When Craig Venter announced that he had created artificial life in 2010 it resulted in splash headlines in media outlets as respectable as The Guardian and convinced lay readers that Venter had succeeded in creating life de novo. https://www.theguardian.com/science/2010/may/20/craig-venter-synthetic-life-form. The project cost 40 million dollars and was addressed by the responsible investigators themselves as representing an advance in the technology of synthetic biology, not in terms of relevance to questions of the origins of life (Gibson et al. 2010).
} 
account of Nature and a fully normative account of Spirit. As Brandom tells us: "How one understands the relation between these, both conceptually and historically, is evidently of the first importance in understanding what Hegel has to teach us about the normative realm he calls 'Geist"' (Brandom 2019). ${ }^{3}$

Hegel, as most clearly and emphatically presented by Brandom, provides a fundamental account of how the very glue that enables the human realm of culture to exist, that integrates and unifies it, is the glue of normativity. Normativity on this level is about a force which constitutes and unifies human life, albeit not a force that can be reckoned in terms of the vocabulary of classical mechanics. Human life entails the existence of self-conscious subjects who are constitutively enmeshed in the force field of reciprocal accountabilities and entitlements. To be a self-conscious subject, is to have a self-identity, to be not just an entity in-itself but an entity for-itself. An entity foritself doesn't exist in a vacuum. To be an entity for-itself is an ongoing social achievement dynamically realized within the normative fabric of human life. As George Herbert Mead argued, a 'self' is a reflective objectification that we discover from a certain social vantage point. There is the self we are as son or daughter, as husband or wife, as father or mother, as teacher or carpenter, and so on. We are neither the passive residue of forces out of our control nor the sovereign dictators of the self we are, we are active in taking stands in each social location about who we are, but our ability to find ourselves to be that self is mediated by the constructive recognition of others. All the possibilities of being a certain self are normatively defined (they are located with the framework of entitlements and accountabilities). To be a being-foritself is thus an on-going accomplishment achieved necessarily within the fabric of social-normative space. ${ }^{4}$

Within the fabric of normatively structured reciprocal accountabilities and entitlements we take a stand on whom we claim we are entitled to be recognized as. And we do so in the context of reciprocally recognizing those whose recognition we require. To speak of entitlements, obligations and accountabilities is to speak of forces (or power in the Foucaultian sense). Hegel famously refers to the I that is a We and the We that is an $I .{ }^{5}$ It can only be a We that enables me to be an I, and thus reciprocally a We can only be a We if it is situated by an I. The obligate relation of I and We describes a special kind of palpable integration and unity. Hegel has done original and foundational work with respect to characterizing the kind of normatively powered unity and integration that constitute the phenomenon of Geist (only in the context of which selves can be selves). But that is not to say that Hegel offers a full-fletched, naturalistic answer to the problem of integration as we've defined it.

For both Leibniz and Kant, normatively resonant entities must necessarily be presupposed and cannot be theoretically derived from pre-normative precursors. As

\footnotetext{
${ }^{3}$ Brandom's much anticipated tome on Hegel had not yet be released as of this writing. The quotations are derived from his 2014 draft of the text made available on his home page https://www.pitt. edu/ brandom/spirit_of_trust.html. The quotation above is from A Spirit of Trust: A Semantic Reading of Hegel's Phenomenology, Part Three Self-Consciousness and Recognition, Chapter Seven: The Structure of Desire and Recognition: Self-Consciousness and Self-Constitution.

${ }^{4}$ For an excellent discussion of Mead's concepts of I and self and of the intersubjective origins of self-hood see Habermas 1992.

${ }^{5}$ Hegel, GWF, Phenomenology of Spirit, (trans. A.V. Miller) Oxford: Oxford University Press, section 177, 110.
} 
fundamental substance Leibniz's monads are as basic as it gets and are always already normatively-infused fully integrated units. Only God could provide the recipe for how to make one. Likewise, the Critical Philosophy holds in principle that neither the origins of the ostensibly purposive functional and organizational unity of any living being, nor certainly that of the normativity of pure practical reason that infuses "Man's moral vocation", could ever be accounted for by (human) theoretical means.

Hegel, by contrast, appears to provide a developmental account in which animal desire becomes an entryway into Geist when desire becomes a desire for recognition. But even the assumption of animal desire is already assuming a unity of purpose that takes the fundaments of what I am calling the really hard problem as an assumed given. Hegel has at least offered the prototype of a dialectical account of movement from a lower to a higher level of unity. Inasmuch as Hegel is, as his famous title suggests, performing a phenomenology of mind, some manner of mindedness is always already assumed. Hegel is thus not accountable to the kind of really hard problem that a contemporary naturalism would pose as it would not be immanent to his phenomenological standpoint. The Absolute, and the Concept, which are ontological primitives for Hegel, supersede the problem of integration and unification in advance, albeit by phenomenological fiat.

Neither a phenomenological nor a transcendental philosophy alone can offer a fully naturalistic account of the basis of integration and unity, given the constitutively methodological assumptions and constraints of each approach. And this is no less the case for Heidegger's existential phenomenology that takes its point of departure from Dasein's practical involvement in her normatively integrated world. But nor is a reductive empiricism the answer to going beyond the limits of a partes extra partes vision of nature. Expressed in very simple terms, neither a science that limits itself entirely to a bottom-up approach, nor a science that limits itself to only a top-down approach, will be able to solve the problem of integration and unification at all levels of nature. What we require is an approach that can bring both of these together in some way. In recent work Arran Gare has made a compelling case for how this involves a renewed acceptance and embrace of speculative thinking (Gare 2018). For physicist Lee Smolin and philosopher Roberto Mangabeira Unger (2015), whose collaborative work over eight years has resulted in a fascinating book entitled The Singular Universe and the Reality of Time, bringing together the big picture of the universe as a whole with the micro-level advances of physics, entails no less than a return to the practice of Natural Philosophy proper. In referring to "normativity as a force of nature", I have thus far only used as a teaser, or perhaps appetizer, the idea that normativity might be able to span the chasm between the bottom up and the top down, and thus serve as a conceptual lynchpin of a renewed speculative natural philosophy. There will be more to come. But it should also be acknowledged that attempting to bring together a top-down with a bottom-up approach, even to also address questions of integration and unification is not entirely new.

Just shy of 100 years ago, Helmuth Plessner, who had trained in both biology and philosophy, put forward the theme of "positionality" as the key concept in an attempt to weave together empirical and phenomenological, bottom-up and top-down, big picture and micro-detail, perspectives into a coherent natural philosophy and philosophical anthropology. Plessner included fundaments about biological structure, organization, 
physiology, ecology, and ethology in his attempt at elaborating a non-dualist, and systematically coherent framework for all forms of life (Plessner 2019).

Using positionalilty as a point of departure for elaborating a logic of life, including human life, is in fact tantamount to simultaneously treating the question of integration, or unification, as a point of departure. As Plessner makes clear, it is only with the living state that boundaries become something other than arbitrary and contingent. To the extent that life is defined by anything, it is defined by the dynamic enactment of a distinction between inner and outer, Plessner's so-called "double aspectivity." "Positionality" then is the categorical universal and sine qua non of the living state and conceptually defines the boundary between physical phenomena that, for all intents and purposes, are partes extra partes, from those for which some non-trivial level of system unity and integrity has been achieved. Plessner does not specifically take up the language of normativity and yet one can find it to be implicit in his account. The realization of a life, even at the most rudimentary, let's say the simple, single-celled level, already entails a form of active mediation between reaching outward and enforcing a boundary, that suggests the regulatory enactment of an implicit norm. For Plessner, there is a logic of dialectical building of positional levels upon levels of reflection that culminate in the human level of "excentric positionality" whereby the "shared" (and invariably normative) perspective of the universal Other is always reflexively embodied and reflectively available. Which is to say that Plessner has long since offered a body-mind neutral account in which human-level normativity is located on a natural continuum in which questions of dynamic system integration are at least implicitly fundamental. Where Plessner fell short, I suggest, is in (only) deriving a largely monological account of the emergence of human-level normativity. ${ }^{6}$ The following may be viewed as in part an attempt to offer the complementary perspective, albeit with the full reconciliatory and synthetic engagement to appear in subsequent work.

\section{Natural detachment and the hybrid hominin}

\subsection{The idea of detachment}

The idea of "detachment" may seem on first pass as a very odd way to begin a discussion about the basis of integration. However, if we begin with some notion of the universe as a whole in a state of a kind of primordial integration then perhaps we can fathom how detachments from a simple and primordial integration would be a precondition for new and perhaps more interesting and intricate forms of integration. When we take the human self (however "natural" doing so may feel) as an unproblematic given we quickly obscure the issue. No matter how you cut it, from any naturalistic point of view, the self is highly derived state of affairs. We can't afford to forget this lest we risk inadvertently tumbling back into metaphysical dualism. There will be a fairly compelling case to be made for the relevance of the idea of detachment

\footnotetext{
${ }^{6}$ CF. my preliminary account of this criticism in my Notre Dame Philosophical Reviews discussion of the recent English translation (Plessner 2019) https://ndpr.nd.edu/news/levels-of-organic-life-and-the-human-anintroduction-to-philosophical-anthropology/.
} 
to the transition (or transitions) constitutive of hominin evolution and indeed this idea goes back to the late eighteenth century. The more speculative mood deigns to propose that detachment can be scaled and tracked all the way down. For present purposes the objective is not to aspire for the idea of detachment to assume the status of a new master theory but rather to lobby for its value in a perspectival sense and in so doing simultaneously affirm the wisdom of some measure of perspectivism in our thinking.

The intuition I wish to arouse is that an entity that claims some measure of detachment is to that extent standing on its own feet, and the greater the level of detachment the more self-standing it is. Detachment then would also suggest internal unity and thus integration, and so must be a kindred concept, and yet detachment is not identical to integration. It can't be identical with integration because, as we will see, there is also a special kind of detachment which is "downward" and disintegrative. More on this later.

Detachment, we will have to assume, begins at the beginning, i.e., with the Big Bang. Prior to the Big Bang, all existence (whatever that means) was confined to an infinitely dense, infinitesimally small singularity in which there was no space or time and all four basic forces of nature (as we now understand them) were united into one. The universe was born, space-time emerges, in an explosion of detachment. Without getting too bogged down in the technical details of high-energy physics and cosmology, the take-home lesson is that a logic of detachments-built-upon-detachments is set into motion from... the beginning. It has been theorized that cosmic detachment began with the detachment of gravity from the unity of fundamental forces, resulting in the formation of elementary particles and anti-particles followed by an inflation into space-time triggered by the further detachment of the strong nuclear force. As yet inexplicable asymmetries in the appearance of baryons (matter) versus antibaryons (anti-matter) were a sine qua non for the early persistence of our universe. It is now believed that the possibility of mass was predicated upon the detachment of the particle called the Higgs boson and with that the associated Higgs field. The detachment of the Higgs boson, and thus of mass, then constitutes a horizon for all subsequent material detachments in our universe.

Physicists characterize the possibility state space of a simple system in terms of its "degrees of freedom." For example, a simple atom like hydrogen can respond to a perturbation (such as being hit by a photon) by moving in space along three axes (3), rotating (4), or elevating the energy level of an electron (5). It is thus accorded five degrees of freedom. A simple diatomic molecule, like $\mathrm{H}_{2}$, can also vibrate along its common axis so adds an additional degree of freedom. Detachment is always about the emergence of higher degrees of relative independence.

We can already see a reciprocal relationship between detachment and integration. Two atoms each with five degrees of freedom, shed their independent degrees of freedom through integrating, by way of a covalent bond, to form a new entity, the diatomic molecule, with six degrees of freedom. The more degrees of freedom the greater the detachment. As our universe has evolved it has given rise to constituent entities with greater and greater abilities to buffer themselves against "ambient winds" (be that bombardment by radiation or predation by voracious carnivores). Following the same logic, a particle with rest mass that creates a well in space-time is more detached than a particle (like a photon) with no rest mass. A macromolecule, like a 
protein-based enzyme, whose folding history affects its future actions is more detached than a simpler molecule whose structure is solely determined by thermodynamic necessity (and thus has no history). A major transition in detachment occurred when a system emerged that actively constituted its own boundary (Plessner's positionality) and actively sustained its ability to do so. We typically associate this level of detachment with what we recognize as "life".

All states of detachment are relative, none are absolute. Levels of detachment exist in nested hierarchies. When a new level of detachment emerges, such as the boundary constituting, self-sustaining system (a simple cell), it also creates a space for downward detachments that may be viewed as parasitic on the higher level of detachment upon which it depends. Viruses emerged as expressions of downward (parasitic) detachment. Parasites and their hosts, lower and higher levels of detachment, dialectically interact resulting in the transformations of each and the appearance of new capacities that neither side of the equation alone could have produced. What begins as an "arms race" between parasites and hosts has resulted in de novo resources that enable parasite and host to re-integrate and make the jump to a new higher level of detachment. Internal compartmentalization and thereby an increase of organizational complexity has been a response strategy of "eukaryotic cells" to parasitic challenge (Koonin 2016) but through symbiotic re-integration has provided the basis for eukaryotes to engage in exploratory processes that lead the way toward both de novo ontogenetic and phylogenetic adaptations. The capacity for active exploratory processes ratchets up the degrees of freedom and level of detachment of a eukaryotic entity by exponential measures. When "variation" (in the Darwinian sense) is no longer principally about the stochastic roll-of-the-dice of enol-keto tautomerism in DNA replication, but rather is facilitated by the active processes of a detached entity and instigated by sensitivity to contingent ambient conditions, when might we be warranted to say that normative-choice making has come into play?

The stark inadequacy of a narrowly-survivalist, Neo-Darwinism was amply revealed by the genome-theoretic debunking of the "junk DNA" thesis, which itself had been a leading inspiration for the far more popularly influential doctrine of the "selfish gene." It has been long-since empirically well-established that the vast majority of human genomic DNA not only doesn't code for unique protein sequences, nor even for noncoding regulatory elements, but rather is highly repetitive and virus-like in its structure. But rather than being merely a genomic "free-rider" as the proponents of the "junk DNA" thesis proclaimed, the endogenous, and potentially transposable and selfreplicating sequences, have been shown to be instrumental in processes of genetic

\footnotetext{
${ }^{7}$ Kirschner and Gerhart (2005), two leading contemporary cell and developmental biologists, updated our understanding of the cellular processes involved in generating novelty, including that of "exploratory processes" and referred to these as the basis of "facilitated variation." That these concepts, based upon unimpeachable empirical evidence, and which radically change the perception of the status of cells and organisms as agents in evolutionary change, haven't filtered into general understanding should well raise questions about the warrants for privileging the continued promulgation of outdated versions of NeoDarwinism as being more rational than myth, ideology or creed. The proper response to the potential dangers of Creationist irrationalism (if such there is) is not the defensive (or offensive) petrification of "classic ideas" that have been made refractory to new findings, new insights and new theories.
} 
segmental duplication that result in species specific, perhaps even species defining, gene families (Moss 2006). The dialectics of detachment suggest that transitions to higher order levels of detachment will attract new rapprochements between competing entities from lower and higher levels of detachment, and thus that downward detachments, seen dialectically, are means toward a variety of different possible sequelae.

When Hegel announced that Spirit is the truth of Nature, he didn't imagine a story being told at a cell and molecular level and yet he offered a perspective that we may find insight-inspiring to generalize upon. The preponderance of philosophical normativists have kept naturalism, one way or another, at arm's length. The very idea, however, of an expansive movement of detachment, indeed a dialectics of detachment, anchors an impetus towards an inevitability of normativity as a force of integration, well beyond the imagination of our speculation-allergic normativists. If the legacy of propositionally-delimited reflection on the nature of normativity inhibits our ability to fathom normativity outside of modern human practice, then perhaps nature is calling upon us to start thinking beyond the constraints of this legacy. The case of the hybrid hominin, I suggest, will provide an enabling pathway toward this end (Moss 2016a). That is also to say, in the spirit of a renewed philosophical anthropology, that when we have met the true missing link, she will be us.

\subsection{The hybrid hominin}

Remarkably, the great majority of both popular and disciplinary accounts of human nature, human evolution, cultural evolution and the like stand oblivious to two elephants in the room, the biological juvenilizing of the human organism, and the uniquely human orientation toward cooperativity and "we-ness." Whereas the former insight has its origins in common-sensical observations of the late eighteenth century which progressively gained more recondite confirmation over the centuries, ${ }^{8}$ the latter is arguably the leading psychological discovery of only twenty-first century human sciences. ${ }^{9}$ Despite this temporal disparity, I will argue that these insights reflect mutually implicative aspects of the hominin we became and continue to be. Hominin neotenous juvenilizing and the hominin orientation toward 'we-ness' will be part of a story about a transition to a new level of detachment that will offer an exemplar for normative integration at a pre-conceptual level with implications ranging both back into pre-hominin existence and forward into the symbolically structured human world as well.

Our two elephants are typically ignored because they fail to coincide with deeply ingrained assumptions about the human individual; the individual human

\footnotetext{
${ }^{8}$ This insight is best thought of as beginning with Gottfried Herder's 1772 award winning "Essay on the Origin of Language" (1986 [1772]) taking theoretical shape with late nineteenth-century theories of neoteny, heterochrony and juvenilization and reaching its philosophical pinnacle with Arnold Gehlen's masterwork Der Mensch (1940) translated into English as Man: His Nature and Place in the World (1988). For details of the late nineteenth-century biological theories see Gould 1977, a recent exposition of the human neoteny view can be found in Bromhall 2003.

9 The work of Michael Tomasello and co-workers at the Max Planck Institute for Evolutionary Anthropology has been a game-changer insofar as establishing the inherent orientation of human infants toward cooperative interactions and the centrality of the human capacity for social understanding and the capacity for "we-mode" as the unique cognitive differentia that distinguishes humans from other higher primates. An easily approachable introduction to these findings can be found in Tomasello 2009 and further explored in Tomasello 2019.
} 
body and the individual human mind. These assumptions have been secured by various traditions and practices not limited to methodological individualism, Neo-Darwinist reductionism, neo-classical economics, rational choice theory, liberal political theory, and so forth. More recent attempts at elaborating cultural evolution theory from a Neo-Darwinist perspective simply follow suit in treating norms as bits of information that competing, self-interested individuals choose to adopt or not for reasons of individual instrumental benefit (Moss 2016b). At its most basic level, human sociality as such, has typically been side-stepped as if it were a non-question. Detachment theory offers a very different account (Moss 2014).

For cognitive psychologist Merlin Donald, the "riddle" of Homo erectus was the provocation that led to a breakthrough in thinking about human sociality (Donald 1991). How was it possible for Homo erectus, a species that endured for over a million years, that domesticated fire and lived in permanent encampments, that produced tools including the Acheulean hand-axe that would have required training to produce, that in greatest likelihood engaged in organized big mammal hunts that would have required a division of labor and who managed to leave Africa and colonize all of the contiguous Euro-Asian land masses (adapting to highly disparate environments and biomes), to do all of this without the benefit of spoken language?

Homo erectus, evidence compels us to conclude, had to have established a fully normatively integrated form of life, and for all intents and purposes was the first form of life to have done so. The thesis being proposed is that the evolution of Homo erectus constituted a radical transition in levels of detachment and we will proceed to draw on the work of various investigators, including Donald, to support this claim. Should this claim be accepted as warranted its implications would include radically undercutting the entire legacy of methodological, ontological and epistemological individualism, making common cause with some like-minded contemporaries in the areas of social ontology and phenomenology and reconfiguring the proper understanding of human freedom and autonomy.

If paleontologists agree on anything, they have agreed that early hominin survival, with the loss of the arboreal cover, required a level and a form of social cohesion unprecedented amongst higher primates. Everything we know about Homo erectus supports the view that an entirely new form of expanded sociality was achieved. But how was this possible? As early as the eighteenth century, Enlightenment thinkers turned their sights onto the human organism and thought about its relationship to the human mind. The common observation was that as organisms, humans are under-specialized weaklings compared to our fellow great apes. It was Gottfried Herder however who grasped the significance of this in detachment theoretic terms (Herder 1986 [1772]). For Herder, the loss of physiological specialization constitutes a detachment from the beck and call of nature (or natural stimuli) and thereby the precondition for a new form of directed attention he called Besonnenheit. On the basis of this simple insight Herder was able to become the grandfather of cultural anthropology. In the absence of behavioral determinations governed by instinctive stimulus-response mechanisms, a new level of integration could take place (and 
indeed had to!). The hominin group could emerge on the basis of unprecedented degrees of freedom to constitute a way of life not by way of inborn-fixed response patterns but by way of the contingent constitution of group norms. Herder referred to a normatively integrated form of life as a Folk (Volk). The practices of a folk are its means of expressively constituting its way of being. Herder was thereby the founder of the expressive-constitutive theory of language $^{10}$ and of the study of folk practices in general that anticipated the birth of cultural anthropology as a discipline. When Franz Boas founded cultural anthropology in the last decade of the nineteenth century, it was expressly understood as a further manifestation of the Herder-Humboldt Volksgeist tradition (Bunzel 1996).

The transition to a new level of detachment in which system integration has become fully normative must have involved both losses and gains of functions such as to result in a net increase in degrees of freedom albeit at the level of the Group. The widespread observation of the radical dependency of the human neonate and the comparative weaknesses of the human individual speak to the evident loss of function; but from a biological standpoint how could these have come about? Evolutionary theory has increasingly become aware of the role that heterochrony, or changes in developmental timing, plays in evolutionary transitions. In the 1920s, the Dutch anatomist Louis Bolk put forward the fetalization thesis suggesting that major human features came as a package through the evolutionary retention of much of the fetal phenotype of the ancestral ape (Gould 1977). This thesis was revived in the form of a contemporary popular science account by English zoologist, writer and filmmaker Bromhall (2003). The ensemble of characteristic human features that resemble those of the fetal but not mature chimpanzee includes the following: an upright head, largely hairless body, massive brain with bulbous skull, flattened face, short lower jaw, small teeth, everted lips, in the female the retention of the outer labia, hymen and frontal position of the vulva, in the male the lack of a fully protective foreskin, lack of a penis bone and lack of spines along the penis. The Belgian anatomist Jos Verhulst also claims that human lungs and heart resemble that of the infant ape (Verhulst 2003). Alongside the fetalization thesis is the observation that the growth pattern of the human neonate's brain for its first year follows that, not of a great ape neonate, but rather that of a fetal brain giving rise to the idea of the human (or hominin) extra-uterine year.

By the lights of the fetalization thesis, the comparative enlargement of the human brain came as part of a systematic developmental package and was not initially selected for enhanced brain power (as the individualist outlook has traditionally assumed). Consistent failure to correlate differences in human intelligence with differences in human brain size would lend some credence to this view. The transition to a fully normatively regulated form of life, a transition that I refer to as the "First Detachment" (of hominin evolution), as already suggested, would necessarily involve both losses and gains - losses with respect to specialized response mechanisms triggered by particular natural stimuli, and gains with respect to the wherewithal for social integration and coordination. The extra-uterine pattern of brain growth can be seen as serving both of

\footnotetext{
${ }^{10}$ Charles Taylor has written on this extensively over his career but most comprehensively in his recent (2016) The Language Animal - The Full Shape of the Linguistic Capacity (The Belknap Press of Harvard University Press).
} 
these requirements simultaneously. By relocating formative stages of brain development to the post-natal environment, basic structural formations become re-situated in a socio-cultural context. This transition fits hand in glove with the seminal work of behavioral ecologist Hrdy (2009). Hrdy's work is crucial for understanding the affective basis of the emergence of the Hominin Group (or supergroup). Comparing relative frequencies of parturition, length of developmental dependency and relative energy cost, Hrdy concluded that it would have been impossible for hominin mothers to have raised their offspring alone. The support of extended caregivers, allo-parents, would have been obligately required. Subsequent studies on post-natal and child-rearing behavior comparing women from various tribal communities with that of great ape mothers confirmed that great ape mothers are far less willing to allow others to hold their infant, and for over greater period of time, than human mothers, and further that only in the case of human mothers is there ever a rejection of a newborn due to some imperfection. Hrdy refers to the affective transition that is introduced by the sharing of infant caregiving at the earliest of stages as the onset of emotional modernity and she likewise concurs that allo-parenting and emotional modernity (i.e., first detachment) begins with Homo erectus. The hominin infant, underdeveloped and under-specialized at birth, and raised by an extended community of caregivers, became the first primate to be affectively well-suited to be a highly integrated member of a social group. The under-specialized neonate not only lacks the innate obstacles to normatively structured, socio-cultural inclusion, but is also in dire need of compensation for what she lacks. The hominin/human infant, as has become well established, has an appetitive drive toward shared attention and cooperative involvement (Tomasello 2009) driven by the need for compensation. The normatively structured world of the Group is the compensation.

Donald (2001) has led the way in terms of emphasizing that hominin evolution has been about the evolution of sociality. The hominin group coheres on the basis of shared emotions, shared perceptions and shared practices. Brains have evolved in relation to the cultures of cognition of which they are part. Mindedness is not an individual phenomenon but a cultural one.

Minds and cultures, being two reciprocal and interdependent aspects of a single phenomenon, are subject to changes that may be looked from either or both bottom up or top-down directions. But contrary to the common assumptions emanating from the reflective mind of the philosopher, there is no reason to assume that the nature of consciousness has been any more static than the nature of cultures and this will point will be elaborated upon further below. Does the kind of consciousness that allowed for First Detachment and the emergence of a flexibly adaptive normative form of life require or presuppose fully and characteristically (as we know it to be) self-conscious individuals? I don't see why it must (and indeed this will become a hallmark of "Second Detachment"). But even if full-on self-consciousness is not necessary for the transition to a fully normative form of life neither is merely the loss of environmentally oriented specialization nor is the affective openness to others sufficient. The lifestyle of Homo erectus was sufficiently complex that there had to be some medium for shared understanding at the requisite level of complexity, and a medium with sufficient semantic degrees of freedom to allow for coordinated responsiveness to contingencies beyond that which merely emotional contagion could provide for. Donald approached this problem, taking a cue from Vygotsky, and contemplating what 
possible game-changing innovation could lie within a plausible zone of proximate evolution. ${ }^{11}$ Great apes, notably chimps, gorillas and bonobos, are seen to possess fairly sophisticated levels of social cognition, yet only within the context of an in-thepresent, social episode. Just on the basis of a fully upright stature, early small-brained hominins (i.e., australopithecines) would have already been able to take full advantage of the upright body as a canvass for expressive gesture within the episode. Donald reasoned that in light of an already highly developed capacity for motor coordination, hominins would be within an evolutionary stone's throw of gaining a de novo capacity for enhanced volitional movement outside of the episode, that mimics movements that have recognizable meaning within an episode. He referred to this capacity as that of autocuing (Donald 1991). The capacity to autocue sequences of movements would have allowed Homo erectus deliberately to redeploy sequences of movements that already have meaning, with communicative intent. Donald refers to this as mimesis and makes the case for how mimesis would have transformed the culture and the cognition of Homo erectus. For present purposes, we can delimit our attention to the way in which mimesis could transform the capacity for normative integration. What does it mean to refer to an entity, or a group of entities, as engaging in a practice? For an activity to be a practice is to ascribe a normative content to it. To engage in a practice is to conform to the right way of doing something. Producing the Acheulean hand-axe was a practice, organizing a division of labor for a hunt would have been a practice, and any ritual, such as a ritual dance, was a practice. Donald suggests that with autocuing Homo erectus gained the capacity for "kinematic imagination", by which he meant the ability to imagine one's body acting in social context as if from an outside perspective. This would seem to coincide well with Helmuth Plessner's concept of "ex-centric positionality" (Plessner 2019) and suggests that ex-centric positionality would have likely begun with Homo erectus. This is not to say that Homo erectus would have enjoyed a full sense of selfhood as we know it, but rather that the embodied foundation of selfhood would have been established and provided the basis upon which symbolically mediated structures could eventually be built. With autocuing, hominins could become implicitly accountable for their actions. The culture and cognition of mimesis created the fabric, for the first time, of a fully normatively integrated form of life. With the culture of mimesis, Hominins entered the realm of Geist, not because they were engaged in explicit self-to-self recognition but because the medium of social integration was that of relations of normative as opposed to physical causality. This claim does constitute an explicit, if perhaps subtle, challenge to the orthodox Hegelian view.

\section{Normativity, pre-reflective plural-self awareness and cerebral asymmetry}

In recent literature concerned with collective intentionality there is a growing debate around the idea of "plural pre-reflective self-awareness." While it is somewhat more widely accepted that there is a minimal pre-reflective me-ness that accompanies our on-

\footnotetext{
${ }^{11}$ Vygotsky analyzed stages and transitions in human development guided by the concept of a zone of proximal development that spoke to what new developmental capacity could plausibly be within reach of what was already present. Donald "exapted" this concept for the evolutionary analysis.
} 
going experience (which has been understood by Dreyfus and others as Heidegger's view), there are many hesitations about the assertion of a pre-reflective us-ness. But what these discussions lack, is exactly the genealogical account that the present theory provides. In order to round out our account of that normatively structured form of life that begins with First Detachment we must draw upon the recent renewal of research on cerebral hemispheric asymmetry inspired by the brilliant work of Scottish neuroscientist McGilchrist (2009). The story he has to offer, and upon which I have drawn some further extrapolations, provides exactly the kind of alternative to the individualistic and cognitivist account of the place of the normative that has impeded naturalistic enterprises from the get-go.

Why have cerebral asymmetry to begin with? The right and left hemispheres perform distinctly different and in principle complementary (and yet also competitive) functions. The right hemisphere is oriented toward the big picture, the holistic context, whereby the left hemisphere is oriented toward a discrete focus. The right hemisphere is responsible for all forms of attention except focused attention, i.e., vigilance, sustained attention, alertness and most of divided attention. Where the left hemisphere is analytic and logical and means-ends oriented, the right hemisphere is both the source of one's emotional style and character and the place where the emotions of another can be interpreted and understood. The right hemisphere is oriented towards end-in-themselves. Where the left hemisphere can judge logical consistency, it can't judge and detect the soundness of premises, even when patently absurd. The right hemisphere can judge the soundness of premises but not necessarily the analytic validity of inferences. As the right hemisphere is context sensitive it can detect and understand a frameshift (a change in context) where the left hemisphere cannot. The right hemisphere provides the location of the body schema and so was presumably instrumental in the transition to autocuing and kinematic imagination. The left hemisphere is parasitic on the right hemisphere to the extent of drawing upon its content for its own form of focal analysis.

That the right hemisphere is heavier in social animals provides some clue as to its history and trajectory. What seems very likely is that the right hemisphere played a role, especially for animals subject to predation, in providing an around-the-clock vigilance of the general surroundings. A moment's reflection will confirm that a) such general ongoing vigilance would make perfect sense for a creature subject to predation, and $b$ ) general vigilance and focused attention are two very different lines of work and having them separated into different hemispheres makes perfect sense as well. When and where mammals become social, the vigilance would concern itself also with the social dynamics of its surrounding environment. The key move I want to make at this point is to suggest that the right hemisphere was poised to become a normativity detector with the transition of First Detachment. We can gain a valuable picture onto what this might look like by referring back to the thesis put forward by former Princeton psychologist Jaynes (1976) in his celebrated The Origin of Consciousness in the Breakdown of the Bicameral Brain. Jaynes argued that there was no indication of self-consciousness as recent as the Iliad and that individuals acted according to what they experienced as the dictates of the voices of the gods that were heard as auditory hallucination produced by the right hemisphere. Jaynes further supported this thesis by the findings of studies done in Wilder Penfield's laboratory, whereby volunteers were subject to electrical stimulation of their right hemisphere resulting in auditory experiences, some but not all of which were experienced as voices, but all of which were experienced as originating 
from a source external to the subject. It would follow, and all the more so given what we now know about the right hemisphere, that the right hemisphere was active in interpreting the normative meaning of its environment which it then announced to the left hemisphere. Consciousness, for Jaynes, in the familiar sense, begins when the left hemisphere commences the narration of a story to oneself about oneself which is based on extrapolation. Whether Jaynes is correct in his reading of the Iliad and his dating of the emergence of self-consciousness to as recently as within 3000 years ago is not crucial for present purposes. What Jaynes depicts with respect to the right hemisphere, pre-self-consciously monitoring the normative indications of its social environment is precisely what would enable Homo erectus, in the absence of speech, to achieve and enact a normatively integrated form of life prior to language. Jaynes' conjectures about the right hemisphere are consistent with the conclusions of McGilchrist decades later, which are also further supported by a wealth of intervening data.

The proposed primordial dominance of the right hemisphere and its role in ongoing normative perception, along with the affective and cognitive resources previously discussed, go a long way towards providing a plausible account of a pre-linguistic group existence, but I will suggest that one more piece of this puzzle must be put in place. I suggest that for a fully normatively integrated form of life to have flourished, as Homo erectus did for something approaching a million years, that there had to be a primordial norm around which all else paid implicit obeisance to, one and only one universal norm, and this was the norm that held that the Group is the Good. It is this Urnorm, this magnetic north, around which all the practices of the group cohered and towards which they were inflected. It is this Ur-norm which allows an affectively and cognitively competent form of life to be constituted by practices that can thereby cohere together. The thesis of the hybrid hominin is that while we are no longer only creatures of the First Detachment Group and are now left-hemisphere dominant, self-narrating, self-conscious individuals, that we are also still creatures of the Group, hence the hybridity. The path toward Second Detachment individuation can also be approached in terms of the integrative force of normativity. Language, the spoken capacity for which is nested in the left hemisphere, was driven by the integrative benefit of rendering the content of ritual into myth. Likewise, the integrative benefits of individual accountability were initially strengthened by the capacity for reflective selfidentification and linguistic mastery of the system of personal pronouns. In detachment-theoretic terms however, human individuation is also a form of downward parasitic detachment, which dialectically speaking has both been instrumental in challenging the limits of the traditional Group in the name of greater, more universal goods, and yet has also served to subvert the normative coherence of any level of human association. A more adequate elaboration of the normative implications of a dialectics of human detachment however must await another day.

There are many implications of the hybrid thesis which pertain to the scope and presence of the "normative force". Schmid (2014), who has defended the idea of a prereflective plural self-awareness, albeit as yet with no thought to a genealogical account, has called to evidence the experience of members of a group cleaving toward a normative desire for agreement as an apparent end-in-itself. Schmid's observation only touches the tip of the iceberg. The legacy of First Detachment continues to orient us toward abstract norms, the diffracted rays of the lost primordial group, above and beyond accountabilities to merely actual people at particular times and places. Children 
of immigrants, for example, whose linguistic exposure is almost entirely limited to their parents during their critical language acquisition phase still manage to become native speakers of the adopted language with no residual accent. These offspring unconsciously privilege their perception of the ambient norm. Even the most accomplished intellectuals will curiously feel themselves to be at a moral disadvantage if they are outnumbered two to one in an argument, despite fully knowing that the vast majority of the as yet uncommitted remaining 7 billion extant humans may well side with their position. Empirical studies in social psychology have shown that, for example, being informed about the facts of waste disposal, waste pollution and recycling has less impact on the typical recycling practices of an individual than finding out what their neighbors are doing (independent of who their neighbors happen to be) (Kesibir 2012). Every term I teach I will invariably encounter students whose internalized norm about not raising their voice will trump the pleadings of a slightly hearing-impaired professor to speak up. The same student who refuses to ask a question, or express a view, in propria persona, will eagerly enter into a protracted peroration just so long as it is understood as the representation of a group of three. One may want to argue that there is "safety in numbers" but I would suggest that this adage is an easy cover for what is at root about the psychology of the Group and not an individualistic expression of a rational choice (about the benefit of numbers). Less anecdotally, I would suggest that the highly influential, if pragmatically ambivalent, Foucauldian concept of Power could be better materialized and made serviceable for human, and even meta-human ${ }^{12}$ benefit, if it was reconstructed as an expression of normative force and further contextualized within a dialectics of detachment. Again, a topic for forthcoming work.

\section{Coda}

Finally, to return to the original question of the very hard problem. Even if it is granted that the thesis of the hybrid hominin can yield new insights into how the force of normativity does and/or doesn't constitute the glue of higher order unities in hominin and human life, is there any hope for imagining that any of this analysis can be backtracked down into progressive strata of pre-hominin life, let alone even so far as the early stages of the universe? Does a dialectics of detachment hold any greater promise for taking us closer to a fuller vision of nature beyond that of just so many parts outside of parts? Detachment theory suggests that all unities are only relative, that the unity we have taken to be most unequivocal, the unit of the self, is in fact derivative of the prior unity of the group, as well as a narrative construct that may conceal as much as it self-articulates. Detachment theory identifies a drive toward higher degrees of independence but in an even more speculative vein could we not also propose a pain of detachment that perhaps even begins with the Big Bang and constitutes a drive toward compensation for the loss of prior unities? Compensation for detachment? In true dialectical fashion, might not every transition in

\footnotetext{
${ }_{12}$ Post-humanism uncritically takes on board an individualistic misconception of the human and proceeds to build its worldview on the basis of an abstract negation of something it misunderstands. Transhumanism begins with the same misconception and moves in another misguided direction (see Moss 2017). Metahumanism, building on detachment theory, will offer an alternative route for sublating anthropocentrism, not by eschewing the human but by exposing the expansiveness immanent of the hybrid hominin's normatively structured dialectics of detachment and compensation. We have become modern, but we were never Human.
} 
detachment, constitute a compensatory re-integration on the one side and yet the paininducing provocation for further compensation on the other? Might it thereby be the case that if we were to at least loosen the ties of our neo-Darwinian and Newtonian vestments, that the hard problem of interiority (consciousness) and the very hard problem of integration might become indistinguishable? Could this be at least a glimpse of that truth that spirit reveals about nature?

Open Access This article is licensed under a Creative Commons Attribution 4.0 International License, which permits use, sharing, adaptation, distribution and reproduction in any medium or format, as long as you give appropriate credit to the original author(s) and the source, provide a link to the Creative Commons licence, and indicate if changes were made. The images or other third party material in this article are included in the article's Creative Commons licence, unless indicated otherwise in a credit line to the material. If material is not included in the article's Creative Commons licence and your intended use is not permitted by statutory regulation or exceeds the permitted use, you will need to obtain permission directly from the copyright holder. To view a copy of this licence, visit http://creativecommons.org/licenses/by/4.0/.

\section{References}

Brandom, R. (2019). A spirit of trust: A reading of Hegel's phenomenology. Cambridge: Belknap Press.

Bromhall, C. (2003). The eternal child. London: Ebury Press.

Bunzel, M. (1996). Franz Boas and the Humboldtian tradition. In G. W. Stocking Jr. (Ed.), Volksgeist as method and ethic: Essays on Boasian ethnography and the German anthropological tradition. Madison: University of Wisconsin Press.

Chalmers, D. (1995). Facing up to the problems of consciousness. Journal of Consciousness Studies, 2(3), 200-219.

Donald, M. (1991). Origins of the modern mind. Cambridge: Harvard University Press.

Donald, M. (2001). A mind so rare: The evolution of human consciousness. New York: W.W. Norton.

Gare, A. (2018). Natural philosophy and the sciences: challenging science's tunnel vision. Philosophies, 3(4), 33-62 https://www.mdpi.com/2409-9287/3/4/33.

Gehlen, A. (1988). Man: His nature and place in the world. New York: Columbia University Press.

Gibson, D.G., Glass, J.I., Lartigue, C., Noskov, V. N., Chuang, R.-Y., Algire, M. A., Benders, G. A., Montague, M. G., Ma, L., Moodie, M. M., Merryman, C., Vashee, S., Krishnakumar, R., AssadGarcia, N., Andrews-Pfannkoch, C., Denisova, E. A., Young, L., Qi, Z.-Q., Segall-Shapiro, T. H., Calvey, C. H., Parmar, P. P., Hutchison, C. A., Smith, H. O., Venter, J. C. (et al.) (2010) "Creation of a bacterial cell controlled by a chemically synthesized genome" Science 329:(5987), 52-56.

Gould, S. J. (1977). Ontogeny and phylogeny. Cambridge: The Belkhap Press of Harvard University Press.

Habermas, J. (1992). Individuation through socialization: On George Herbert mead's theory of subjectivity. In: Habermas, J. Postmetaphysical thinking: Philosophical essays (trans. Mark Hohengarten) Cambridge: Polity Press.

Herder, J.G. (1986 [1772]). Essay on the Origin of Language. In: On the origin of language two essays. Jean-Jacques Rousseau Johann Gottfried Herder (trans J. Moran \& A Gode). Chicago: University of Chicago Press.

Hrdy, S. (2009). Mothers and others. Cambridge: Harvard University Press.

Jaynes, J. (1976). The origins of consciousness in the breakdown of the bicameral mind. New York: Houghton Mifflin.

Kesibir, S. (2012). The superorganism account of human sociality: how and when human groups are like beehives. Personality and Social Psychology Review, 16, 233-261.

Kirschner, M. W., \& Gerhart, J. C. (2005). The plausibility of life: Resolving Darwin's dilemma. New Haven: Yale University Press.

Koonin, E. V. (2016). Viruses and mobile elements as drivers of evolutionary transitions. Philosophical Transactions Royal Society B, 371, 20150442.

McGilchrist, I. (2009). The master and his emissary: The divided brain and the making of the western world. New Haven: Yale University Press.

Moss, L. (2006). Redundancy, plasticity, and detachment: The implications of comparative genomics for evolutionary thinking. Philosophy of Science, 73(5), 930-946.

Moss, L. (2014). Detachment and compensation. Philosophy \& Social Criticism, 40(1), 91-105. 
Moss, L. (2016a). The hybrid hominin: A renewed point of departure for philosophical anthropology. In P. Honenberger (Ed.), Naturalism and philosophical anthropology: nature, life, and the human between transcendental and empirical perspectives. New York: Palgrave Macmillan.

Moss, L. (2016b). Review: Tim Lewens, cultural evolution: conceptual challenges, Notre Dame Philosophical Reviews. https://ndpr.nd.edu/news/cultural-evolution-conceptual-challenges/. Accessed 4 May 2016.

Moss, L. (2017). New naturalism and critical theory. In A. Gare \& W. Hudson (Eds.), For a new naturalism. New York: Telos Press.

Plessner, H. (2019). Levels of organic life and the human: An introduction to philosophical anthropology (trans. M Hyatt). New York: Fordham University Press.

Schmid, H. B. (2014). Plural self-awareness. Phenomenology and the Cognitive Sciences, 13, 7-24.

Tomasello, M. (2009). Why we cooperate. Cambridge: The MIT Press.

Tomasello, M. (2019). Becoming human: A theory of ontogeny. Cambridge: Belknap Press.

Unger, R. M., \& Smolin, L. (2015). The singular universe and the reality of time. A proposal in natural philosophy. Cambridge: Cambridge University Press.

Verhulst, J. (2003). Developmental dynamics in humans and other primate: Discovering evolutionary principles through comparative morphology. Adonis Press.

Publisher's note Springer Nature remains neutral with regard to jurisdictional claims in published maps and institutional affiliations. 